УДК 342.7

$10.17213 / 2075-2067-2021-4-66-72$

\title{
ОСОБЕННОСТИ ЗАЩИТЫ ПРАВ ПОТРЕБИТЕЛЕЙ ПРИ ДИСТАНЦИОННОЙ ПОКУПКЕ ЛЕКАРСТВЕННЫХ СРЕДСТВ
}

\author{
(C) 2021 г. Н. Ф. Мирочниченко
}

\section{Южно-Российский государственный политехнический университет (НПИ) имени М. И. Платова, г. Новочеркасск, Россия}

Целью исследования является детальный правовой анализ розничной дистанционной торговли лекарственными препаратами для медицинского применения, а также правовой анализ возможности обмена и возврата денежных средств за лекарственный препарат.

Методологическую базу исследования составляют анализ нормативно-правовых актов, регулирующих розничную торговлю, в том числе дистанционную, лекарственными препаратами для медииинского применения, сравнение, обобщение.

Результаты исследования. Правовой анализ нормативно-правовых актов, регулирующих розничную дистанциионную торговлю лекарственными препаратами для медицинского применения, а также правовой анализ возможности обмена и возврата денежных средств за лекарственный препарат установил, что так как лекарственные препараты входят в перечень непродовольственных товаров надлежащего качества, не подлежащих обмену, то соответственно, лекарственные препараты надлежсащего качества, вернуть или обменять нельзя [3, cm. 410; 4, cm. 140; 9, cm. 593]. Но при дистанционной покупке лекарственного препарата для медицинского применения за покупателем (потребителем) законодатель закрепил право отказаться от доставленного лекарственного препарата надлежсащего качества до оплаты заказа (услуга доставки оплачивается), а также право возврата заказа ненадлежащего качества (например, брак, дефекты маркировки, отсутствие инструкции по применению препарата, истекиий срок годности, если доставленный заказ не соответствует заказанному по количеству или составу) без оплаты самого заказа и услуги по его доставке.

Перспективу исследования составляет правовой анализ судебной практики в сфере защиты прав потребителей при дистанционной покупке лекарственных препаратов.

Ключевые слова: защита прав потребителей; лекарственные препараты; дистанщионная продажа; возврат денежных средств.

\section{FEATURES OF CONSUMER RIGHTS PROTECTION IN REMOTE PURCHASE OF MEDICINES}

\section{(C) 2021 N. F. Miroshnichenko}

\section{Platov South Russian State Polytechnic University (NPI), Novocherkassk, Russia}

The purpose of the study is a detailed legal analysis of retail remote trade in medicines for medical use, as well as a legal analysis of the possibility of exchanging and returning funds for a drug.

The methodological basis of the study is the analysis of regulatory legal acts regulating retail trade, including remote trade, with medicines for medical use, comparison, and generalization. 
The results of the study. The legal analysis of the normative legal acts regulating retail remote trade in medicines for medical use, as well as the legal analysis of the possibility of exchanging and returning money for a medicinal product, established that, since medicines are included in the List of non-food products of proper quality that are not subject to exchange, respectively, medicines of proper quality cannot be returned or exchanged [3, Article 410; 4, Article 140; 9, Article 593]. However, in the case of remote purchase of a medicinal product for medical use, the buyer (consumer) has the right to refuse the delivered medicinal product of proper quality before paying for the order (the delivery service is paid for), as well as the right to return the order of improper quality (for example, marriage, labeling defects, lack of instructions for the use of the drug, expired expiration date, if the delivered order does not match the ordered quantity or composition) without paying for the order itself and its delivery service.

The perspective of the study is the legal analysis of judicial practice in the field of consumer protection in the remote purchase of medicines.

Key words: consumer protection; medicines; remote sale; refund of funds.

Введение. Проблема защиты прав потребителей при покупке лекарственных препаратов является сегодня одной из актуальных ввиду того, что до недавнего времени большинство граждан России находились на самоизоляции по причине новой инфекции, органы власти внесли соответствующие поправки в законодательство, закрепив право аптечных организаций осуществлять розничную торговлю лекарственными препаратами для медицинского применения дистанционным способом, то есть теперь купить лекарственные препараты возможно через Интернет. Вместе с тем сразу возникли вопросы по обмену или возврату лекарственных средств.

Целью исследования данной статьи является детальный правовой анализ розничной дистанционной торговли лекарственными препаратами для медицинского применения, а также правовой анализ возможности обмена и возврата денежных средств за лекарственный препарат и определение последовательности действий при возникновении необходимости в обмене и возврате денежных средств за приобретенный лекарственный препарат.

Для достижения вышеуказанной цели были сформулированы следующие задачи:

1) провести детальный правовой анализ законодательства, регулирующего розничную дистанционную торговлю лекарственными препаратами для медицинского применения;
2) провести детальный правовой анализ положений законодательства, регулирующих возможность обмена и возврата денежных средств за лекарственный препарат;

3) выявить последовательность действий при обмене и возврате денежных средств за лекарственный препарат.

Правовое регулирование обращения лекарственных средств. Правовое регулирование обращения лекарственных средств на территории РФ регулируется Федеральным законом №61-Ф3 «Об обращении лекарственных средств» от 12.04.2010 г.

3 апреля 2020 года был принят Федеральный закон №105-Ф3 «О внесении изменений в Федеральный закон “Об обращении лекарственных средств”», согласно указанным изменениям аптеки теперь имеют право реализовывать лекарственные препараты дистанционно.

Постановление Правительства РФ от 16.05.2020 г. №697 (ред. от 11.07.2020 г.) утвердило «Правила выдачи разрешения на осуществление розничной торговли лекарственными препаратами для медицинского применения дистанционным способом, осуществления такой торговли и доставки указанных лекарственных препаратов гражданам», а также внесло изменения в акты Правительства Российской Федерации по вопросу розничной торговли лекарственными препаратами для медицинского применения дистанционным способом. 
Так, в Федеральном законе №61-Ф3 определено: фармацевтическая деятельность деятельность, включающая в себя оптовую торговлю лекарственными средствами, их хранение, перевозку и (или) розничную торговлю лекарственными препаратами, в том числе дистанционным способом, их отпуск, хранение, перевозку, изготовление лекарственных препаратов [5, ст. 1815]. Лекарственные препараты - лекарственные средства в виде лекарственных форм, применяемые для профилактики, диагностики, лечения заболевания, реабилитации, для сохранения, предотвращения или прерывания беременности. Статья 55 вышеуказанного закона устанавливает, что розничная торговля лекарственными препаратами для медицинского применения может осуществляться дистанционнылм способом аптечными организациями, имеющими лицензию на фармацевтическую деятельность и соответствующее разрешение федерального органа исполнительной власти, осуществляющего функции по контролю и надзору в сфере здравоохранения препаратов [5, ст. 1815].

\section{Правила дистанционной торговли} и доставки лекарственных средств. Продажа лекарственных средств дистанционно включает в себя: 1) прием заказа; 2) формирование заказа; 3) хранение заказа; 4) доставку заказа.

1. Прием заказов производится при помощи сети Интернет через сайт или мобильное приложение аптечной организации и по телефонам службы заказа, справочной службы.

Расчеты при оплате лекарственных препаратов и услуг по их доставке осуществляются по выбору покупателя в наличной или безналичной форме путем предоплаты заказа или его оплаты в месте получения заказа.

Аптечная организация обязана обеспечить конфиденциальность персональных данных покупателя в соответствии с требованиями законодательства Российской Федерации.

При приеме заказов на продажу лекарственных средств дистанционно уполномоченный работник аптечной организации обязан:

- проинформировать покупателя о показаниях к применению приобретаемого им лекарственного средства, его цене, правилах хранения, взаимодействии с другими лекарственными препаратами, сроке годности, условиях отпуска;

- заключить с покупателем договор розничной купли-продажи с условием доставки, в котором указываются срок формирования и стоимость заказа, стоимость услуги по доставке заказа, возможность его получения по месту нахождения аптечной организации или доставки по месту жительства (пребывания, фактического нахождения) покупателя, иному адресу, согласованному с покупателем, способ и место оплаты приобретаемого им лекарственного препарата;

- согласовать с покупателем необходимость предоставления документов, подтверждающих качество лекарственных препаратов при их доставке вне места нахождения аптечной организации.

Договор купли-продажи считается заключенным с момента выдачи аптечной организацией покупателю кассового или товарного чека либо иного документа, подтверждающего оплату товара, или с момента получения аптечной организацией сообщения о намерении покупателя приобрести лекарственные препараты.

2. Сформированный заказ упаковывается в герметичную транспортную упаковку, обеспечивающую защиту лекарственных препаратов от внешнего воздействия в зависимости от условий хранения в соответствии с инструкциями по медицинскому применению лекарственных препаратов и возможность подтверждения факта вскрытия.

На заказ оформляется опись вложения с указанием номера заказа, даты и времени сборки, которая подписывается уполномоченным работником аптечной организации.

3. Аптечная организация ведет регистрацию заказов и доставок лекарственных препаратов с указанием даты, времени и номера заказа, наименований лекарственных препаратов и их производителей, лекарственных форм, форм выпуска, информации о времени, дате и адресе доставки заказа покупателю, а также вносит информацию об оплаченных (отпущенных) и полученных покупателем лекарственных препаратах в систему мониторинга движения лекарственных препаратов для медицинского применения. 
4. Доставка заказа производится работником аптечной организации или другой организации. Заказ передается покупателю по месту его жительства (пребывания, фактического нахождения) или иному указанному им адресу, а при отсутствии покупателя лицу, предъявившему оригиналы или копии (возможно в электронном виде) квитанции или иного документа, подтверждающего заключение договора купли-продажи, оплату заказа или оформление его доставки.

При доставке лекарственных средств, требующих поддержания определенного температурного режима, применяется соответствующее оборудование.

При получении заказа покупатель проверяет целостность транспортной упаковки, самостоятельно вскрывает транспортную упаковку, сверяет содержимое заказа с описью вложения, проверяет отсутствие повреждений вторичной (потребительской) и первичной упаковок лекарственного препарата, надлежащий вид лекарственного препарата (при возможности), расписывается в получении заказа и в подтверждении отсутствия претензий к аптечной организации и службе доставки.

Возврат доставленного лекарственного препарата. Лекарственные средства надлежащего качества вернуть или обменять нельзя [3, ст. 410; 4, ст. 140; 9, ст. 593]. Но, если продавец не проинформировал покупателя о показаниях к применению приобретаемого им лекарственного препарата, его цене, сроке годности, условиях отпуска, правилах хранения, взаимодействии с другими лекарственными препаратами, покупатель вправе вернуть данный препарат и потребовать от продавца возврата уплаченной за них суммы, даже если лекарственные препараты качественные [3, ст. 410].

Кроме того, у покупателя теперь появилось право отказаться от доставленного лекарственного препарата надлежащего качества до оплаты заказа. В этом случае оплачивается только услуга по доставке [7, ст. 3278].

В случае доставки заказа ненадлежащего качества (ненадлежащее качество лекарственного препарата, дефекты маркировки, отсутствие инструкции по применению препарата, истекший срок годности, доставленный заказ не соответствует заказанному по количеству или составу,) покупатель вправе вернуть его работнику, осуществляющему доставку, без оплаты доставленного лекарственного препарата и (или) услуги по его доставке и (или) потребовать надлежащее исполнение заказа.

Если аптечная организация отказывается добровольно вернуть денежную сумму за оплаченное лекарственное средство, то необходимо составить претензию с вышеуказанным требованием и направить ее продавцу. Претензия составляется в двух экземплярах в свободной письменной форме. В претензии необходимо указать информацию о том, кому направляется претензия (полное наименование аптечной организации, адрес), данные покупателя (фамилия, имя, отчество, адрес, телефон) и изложить суть претензии (название лекарственного средства, дата и место его приобретения, способ оплаты и обнаруженные недостатки) и требование покупателя о возврате денежных средств или замене лекарственного средства [3, ст. 410]. Кроме того, к претензии необходимо приложить копии документов, подтверждающих покупку и оплату лекарственного средства.

Если аптечная организация отказывает удовлетворить требование покупателя в добровольном порядке, то покупатель имеет право обратиться в суд с исковым заявлением о возврате уплаченной за лекарственное средство суммы, а также потребовать возмещения убытков, причиненных вследствие ненадлежащего информирования о лекарственном средстве или продажи лекарственного средства ненадлежащего качества.

Заключение. Проведенный правовой анализ нормативно-правовых актов, регулирующих розничную дистанционную торговлю лекарственными препаратами для медицинского применения, и нормативно-правовых актов, регулирующих возможность возврата денежных средств за лекарственный препарат, выявил, что лекарственные препараты входят в перечень непродовольственных товаров надлежащего качества, не подлежащих обмену, следовательно, по общему правилу лекарственные препараты надлежащего качества, приобретенные непосредственно в аптеке, вернуть или обменять нельзя. Но теперь законодатель закрепил за покупателем право 
отказаться от доставленного лекарственного препарата надлежащего качества до оплаты заказа - в случае покупки лекарственного средства дистанционно - оплачивается только услуга по доставке [7, ст. 3278].

В случае доставки заказа ненадлежащего качества (ненадлежащее качество лекарственного препарата, дефекты маркировки, отсутствие инструкции по применению препарата, истекший срок годности, доставленный заказ не соответствует заказанному по количеству или составу) покупатель вправе вернуть его работнику, осуществляющему доставку, без оплаты доставленного лекарственного препарата и (или) услуги по его доставке и (или) потребовать надлежащее исполнение заказа.

Если аптечная организация отказывается добровольно вернуть денежную сумму за оплаченное лекарственное средство, то необходимо составить претензию с вышеуказанным требованием и направить ее продавцу - аптечной организации.

Если аптечная организация отказывает в удовлетворении требования покупателя в добровольном порядке, покупатель имеет право обратиться в суд с исковым заявлением о возврате уплаченной за лекарственное средство суммы, а также потребовать возмещения убытков, причиненных вследствие продажи лекарственного средства ненадлежащего качества.

\section{Литература}

1. Конституция Российской Федерации (принята всенародным голосованием 12.12.1993 г. с изменениями, одобренными в ходе общероссийского голосования 01.07.2020 г.) [Электронный ресурс] / Официальный текст Конституции РФ с внесенными поправками от 14.03.2020 г. Официальный интернет-портал правовой информации. Режим доступа: http://www.pravo.gov.ru.

2. Гражданский кодекс Российской Федерации (часть первая) от 30.11.1994 г. №51Ф3 (ред. от 09.03.2021 г.) // Собрание законодательства РФ. - 05.12.1994. - №32. Ст. 3301.

3. Гражданский кодекс Российской Федерации (часть вторая) от 26.01.1996 г. №14-Ф3 (ред. от 09.03.2021 г.) // Собрание законодательства РФ. - 29.01.1996. — №5. - Ст. 410.
4. Закон РФ от 07.02.1992 г. №2300-1 (ред. от 22.12.2020 г.) «О защите прав потребителей» // Собрание законодательства РФ. - 15.01.1996. - №3. - Ст. 140.

5. Федеральный закон от 12.04.2010 г. №61-Ф3 (ред. от 22.12.2020 г.) «Об обращении лекарственных средств» (с изм. и доп., вступ. в силу с 01.01.2021 г.) // Собрание законодательства РФ. - 2010. — №16. - Ст. 1815.

6. Федеральный закон от 03.04.2020 г. №105-Ф3 «О внесении изменений в статью 15.1 Федерального закона «Об информации, информационных технологиях и о защите информации» и Федеральный закон «Об обращении лекарственных средств» // Собрание законодательства РФ. - 06.04.2020. №14 (часть I). — Ст. 2035.

7. Постановление Правительства РФ от 16.05.2020 г. №697 (ред. от 11.07.2020 г.) «Об утверждении Правил выдачи разрешения на осуществление розничной торговли лекарственными препаратами для медицинского применения дистанционным способом, осуществления такой торговли и доставки указанных лекарственных препаратов гражданам и внесении изменений в некоторые акты Правительства Российской Федерации по вопросу розничной торговли лекарственными препаратами для медицинского применения дистанционным способом» // Собрание законодательства РФ. - 25.05.2020. №21. - Ст. 3278.

8. Постановление Правительства РФ от 31.12.2020 г. №2463 «Об утверждении Правил продажи товаров по договору розничной купли-продажи, перечня товаров длительного пользования, на которые не распространяется требование потребителя о безвозмездном предоставлении ему товара, обладающего этими же основными потребительскими свойствами, на период ремонта или замены такого товара, и перечня непродовольственных товаров надлежащего качества, не подлежащих обмену, а также о внесении изменений в некоторые акты Правительства Российской Федерации» // Собрание законодательства РФ. — 18.01.2021. — №3. - Ст. 593.

\section{References}

1. Konstitucija Rossijskoj Federacii (prinjata vsenarodnym golosovaniem 12.12.1993 
g. s izmenenijami, odobrennymi v hode obshherossijskogo golosovanija 01.07.2020 g.) [The Constitution of the Russian Federation (adopted by popular vote on 12.12.1993 with amendments approved during the All-Russian vote on 01.07.2020)] [Jelektronnyj resurs] / Oficial'nyj tekst Konstitucii RF s vnesennymi popravkami ot 14.03.2020 g. Oficial'nyj internet-portal pravovoj informacii [The official text of the Constitution of the Russian Federation as amended on 14.03.2020. The official Internet portal of legal information]. — URL: http://www.pravo. gov.ru.

2. Grazhdanskij kodeks Rossijskoj Federacii (chast' pervaja) ot 30.11.1994 g. №51-FZ (red. ot 09.03.2021 g.) [The Civil Code of the Russian Federation (part one) of 30.11.1994 №51-FZ (ed. of 09.03.2021)] // Sobranie zakonodatel'stva RF [Collection of legislation of the Russian Federation]. - 05.12.1994. - №32. - Article 3301.

3. Grazhdanskij kodeks Rossijskoj Federacii (chast' vtoraja) ot 26.01.1996 g. №14-FZ (red. ot 09.03.2021 g.) [The Civil Code of the Russian Federation (part two) of 26.01.1996 №14-FZ (ed. of 09.03.2021)] // Sobranie zakonodatel'stva RF [Collection of legislation of the Russian Federation]. - 29.01.1996. — №5. — Article 410.

4. Zakon RF ot 07.02.1992 g. №2300-1 (red. ot 22.12 .2020 g.) $« \mathrm{O}$ zashhite prav potrebitelej» [The Law of the Russian Federation of 07.02.1992 №2300-1 (ed. of 22.12.2020) «On protection of consumer rights»] // Sobranie zakonodatel'stva RF [Collection of legislation of the Russian Federation]. - 15.01.1996. — №3. - Article 140.

5. Federal'nyj zakon ot 12.04.2010 g. №61FZ (red. ot 22.12.2020 g.) «Ob obrashhenii lekarstvennyh sredstv») (s izm. i dop., vstup. V silu s 01.01.2021 g.) [Federal Law №61-FZ of 12.04.2010 (ed. of 22.12.2020) «On the circulation of medicines» (with amendments and additions, intro. effective from 01.01.2021)] // Sobranie zakonodatel'stva RF [Collection of legislation of the Russian Federation]. - 2010. №16. - Article 1815.

6. Federal'nyj zakon ot 03.04.2020 g. №105-FZ «O vnesenii izmenenij v stat'ju 15.1 Federal'nogo zakona $« \mathrm{Ob}$ informacii, informacionnyh tehnologijah i o zashhite informacii» i Federal'nyj zakon «Ob obrashhenii lekarstvennyh sredstv»» [Federal Law №105-FZ of 03.04.2020 «On Amendments to Article 15.1 of the Federal Law «On Information, Information Technologies and Information Protection» and the Federal Law «On the Circulation of Medicines»] // Sobranie zakonodatel'stva RF [Collection of legislation of the Russian Federation]. — 06.04.2020. — №14 (chast' I). Article 2035.

7. Postanovlenie Pravitel'stva RF ot 16.05.2020 g. №697 (red. ot 11.07.2020 g.) «Ob utverzhdenii Pravil vydachi razreshenija na osushhestvlenie roznichnoj torgovli lekarstvennymi preparatami dlja medicinskogo primenenija distancionnym sposobom, osushhestvlenija takoj torgovli i dostavki ukazannyh lekarstvennyh preparatov grazhdanam i vnesenii izmenenij $\mathrm{v}$ nekotorye akty Pravitel'stva Rossijskoj Federacii po voprosu roznichnoj torgovli lekarstvennymi preparatami dlja medicinskogo primenenija distancionnym sposobom» [Resolution of the Government of the Russian Federation of 16.05.2020 №697 (ed. of 11.07.2020) «On approval of the Rules for issuing permits for the retail sale of medicines for medical use by remote means, the implementation of such trade and delivery of these medicines to citizens and amendments to some acts of the Government of the Russian Federation on the retail sale of medicines for medical use by remote means»] // Sobranie zakonodatel'stva RF [Collection of legislation of the Russian Federation]. - 25.05.2020. №21. - Article 3278.

8. Postanovlenie Pravitel'stva RF ot 31.12.2020 g. №2463 «Ob utverzhdenii Pravil prodazhi tovarov po dogovoru roznichnoj kupli-prodazhi, perechnja tovarov dlitel'nogo pol'zovanija, na kotorye ne rasprostranjaetsja trebovanie potrebitelja o bezvozmezdnom predostavlenii emu tovara, obladajushhego jetimi zhe osnovnymi potrebitel'skimi svojstvami, na period remonta ili zameny takogo tovara, i perechnja neprodovol'stvennyh tovarov nadlezhashhego kachestva, ne podlezhashhih obmenu, a takzhe o vnesenii izmenenij v nekotorye akty Pravitel'stva Rossijskoj Federacii»» [Resolution of the Government of the Russian Federation №2463 of 31.12.2020 «On approval of the Rules for the sale of goods under a retail sale agreement, a list of durable goods that are not subject to the Consumer's requirement to provide him with goods having the same basic consumer properties free of charge for the 
period of repair or replacement of such goods, and a list of non-food goods of proper quality that are not subject to exchange, as well as on Amendments to Certain acts of the Govern- ment of the Russian Federation»] // Sobranie zakonodatel'stva RF [Collection of legislation of the Russian Federation]. — 18.01.2021. №3. - Article 593.

Мирошниченко Наталья Федоровна - ассистент кафедры «Юриспруденция» Южно-Российского государственного политехнического университета (НПИ) имени М.И. Платова.

Miroshnichenko Natalia Fedorovna - Assistant Professor of the Department of Jurisprudence, Platov South Russian State Polytechnic University (NPI).

346428, г. Новочеркасск, ул. Просвещения, 132

132 Prosveshcheniya st., 346428, Novocherkassk, Russia

E-mail: nadiviev@yandex.ru 